\title{
Response of three Glycine species to salt stress
}

\author{
Wen-Yuan Kao a,b,c,*, Tyng-Tyng Tsai ${ }^{\mathrm{c}}$, Hung-Chieh Tsai ${ }^{\mathrm{c}}$, Chen-Ning Shih ${ }^{\mathrm{c}}$ \\ ${ }^{a}$ Department of Life Science, National Taiwan University, Taipei, Taiwan, ROC \\ ${ }^{\mathrm{b}}$ Institute of Ecology and Evolutionary Biology, National Taiwan University, Taipei, Taiwan, ROC \\ ${ }^{\mathrm{c}}$ Institute of Botany, Academia Sinica, Taipei, Taiwan, ROC
}

Received 21 June 2004; accepted 18 January 2005

\begin{abstract}
Responses of leaf area, biomass, photosynthetic gas exchange and ion contents to four $\mathrm{NaCl}$ treatments, $0,17,51$, and $85 \mathrm{mM} \mathrm{NaCl}$, were examined for three wild soybean species (Glycine soja, Glycine tomentella and Glycine tabacina). In G. soja, NaCl treatment for 2 months reduced the photosaturated photosynthetic rate $\left(A_{\max }\right)$, leaf area and biomass of $\mathrm{NaCl}$ treated plants relative to control treatments. Reductions were larger at higher $\mathrm{NaCl}$ concentrations. Similar changes were found in G. tabacina, however, the reductions were less than those in G. soja. In G. tomentella, significant reductions in $A_{\max }$ and biomass were found in 51 and $85 \mathrm{mM} \mathrm{NaCl}$ treated plants, but not in $17 \mathrm{mM}$ concentrations. Results imply that the three species have differentiated in their sensitivity to salinity, with $G$. soja being the most sensitive, G. tabacina intermediate, and G. tomentella the least sensitive. The three species also differed in leaf tissue concentrations of Na and K. A negative correlation between $\mathrm{Na}$ accumulation in leaf tissue and salt tolerance was found that contrasted to a positive correlation between $\mathrm{K}$ concentration in leaf tissue and salt tolerance.
\end{abstract}

(C) 2005 Elsevier B.V. All rights reserved.

Keywords: Glycine; Ion contents; Photosynthesis; Salinity

\section{Introduction}

In glycophytes, plant growth and development are generally limited by salinity. Most of the world's crop species are glycophytes, hence they do not grow under high soil salinity. However, with increasing amounts of arable land undergoing salinization (Szabolcs, 1994) and increasing food demand from the growing human population, the need to develop salt-tolerant crop varieties is unavoidable. To develop salt-tolerant crops, it is necessary to identify the degree of salinity tolerance within crops and their wild-type relatives. Investigations of genetically based differences between closely related plants are particularly important because these studies provide necessary information to select traits for

\footnotetext{
Abbreviations: $A_{\max }$, photosaturated photosynthetic rate; $C_{\mathrm{a}}$, ambient $\mathrm{CO}_{2}$ concentration; $C_{\mathrm{i}}$, intercellular $\mathrm{CO}_{2}$ concentration; $g_{\mathrm{s}}$, stomatal conductance; HS, $85 \mathrm{mM} \mathrm{NaCl}$; LS, $17 \mathrm{mM} \mathrm{NaCl}$; MS, $51 \mathrm{mM} \mathrm{NaCl}$; 0S, $0 \mathrm{mM}$ $\mathrm{NaCl}$

* Corresponding author. Tel.: +8862 33662511; fax: +886223673374.

E-mail address: wykao@ntu.edu.tw (W.-Y. Kao).
}

breeding salt-tolerant crops (Tester and Davenport, 2003). Recent studies have found differences among rice (Lee et al., 2003), barley (Gorham et al., 1994; Flowers and Hajibagheri, 2001), maize (Fortmeier and Schubert, 1995) and wheat (Nagy and Galiba, 1995) cultivars in their response to salinity.

There are three wild soybean species in Taiwan, Glycine soja Sieb \& Zucc., Glycine tomentella Hayata and Glycine tabacina (Labill.) Benth. Morphological and physiological differences in response to water availability have been reported previously for these three species, corresponding to differences in the water availability of their native habitats (Kao and Tsai, 1998). Plant responses to salt and water stress have much in common (Munns, 2002); however, they are not necessarily linked (Nagy and Galiba, 1995). G. tomentella is the only one of the species that has been found growing in seaside habitats (Huang and Ohashi, 1993). In this study, we test the hypothesis that in addition to their differences in response to drought (Kao and Tsai, 1998), the three wild soybeans have also differentiated in their sensitivity to salinity. If so, the wild soybean species might provide information 
relevant to the selection of traits leading to more salt-tolerant soybean cultivars.

In addition to show reductions in growth, a typical response of glycophytic plants subjected to saline conditions is a reduction in photosynthetic rates (Bongi and Loreto, 1989; Brugnoli and Lauteri, 1991; Seemann and Critchley, 1985; Walker et al., 1981). Decreased photosynthetic rates may result from the closure of stoma, induced by osmotic stress, or from salt-induced damage to the photosynthetic apparatus (reduced efficiency of the electron transport chain and damage to the light harvesting complex). Accordingly, we conducted measurements of photosynthetic gas exchange to examine the comparative effects of salinity on net $\mathrm{CO}_{2}$ assimilation and stomatal conductance among the three study species.

One mechanism associated with greater tolerance of moderately saline environments is the ability of plants to exclude $\mathrm{Na}$ from the shoot, and concurrently maintain high levels of shoot K (Schachtman and Munns, 1992; Gorham et al., 1994; Flowers and Hajibagheri, 2001). Salinity has been shown to interfere with K and Ca nutrition (Rengel, 1992) and this can cause nutrient deficiencies. In this study, we measured the $\mathrm{K}$, $\mathrm{Na}$ and $\mathrm{Ca}$ ion contents of leaves from the three wild soybean species subjected to $\mathrm{NaCl}$ to investigate possible mechanisms for differential salt sensitivity among the species.

The main objective of this study was to determine whether there was variation among the three wild soybean species in their response to salinity.

\section{Materials and methods}

\subsection{Plant materials}

G. soja Sieb \& Zucc. seeds were collected from Shihmen $\left(25^{\circ} 02^{\prime} \mathrm{N}, 120^{\circ} 30^{\prime} \mathrm{E}\right)$ in northern Taiwan, G. tomentella Hayata from Hengchun $\left(22^{\circ} 00^{\prime} \mathrm{N}, 120^{\circ} 44^{\prime} \mathrm{E}\right)$ in southern Taiwan, and G. tabacina (Labill.) Benth from Penghu island $\left(23^{\circ} 34^{\prime} \mathrm{N}, 119^{\circ} 33^{\prime} \mathrm{E}\right)$ (Kao and Tsai, 1998). Seeds were germinated in Petri dishes, followed by transplanting of the seedlings to $2 \mathrm{~L}$ plastic pots. One seedling was planted in each pot, which was filled with a mixture of 1:1 vermiculite:soil by volume. Plants were grown in a glasshouse in natural daylight, watered every day, and fertilized using inorganic fertilizer (20 N:20 P:20 K) once every 2 weeks. The air temperature and relative humidity in the glasshouse was maintained between 30 and $35^{\circ} \mathrm{C}$ and $70 \%$, respectively. The salinity treatments began when plants were 4 weeks old. The pots were immersed in a modified Hoagland's solution (Haines and Dunn, 1976), containing 0, 17, 51, and $85 \mathrm{mM}$ of $\mathrm{NaCl}$, for $2 \mathrm{~h}$ every day, with four replicates per species for each salinity treatment. Final $\mathrm{NaCl}$ treatment concentrations were reached gradually by increments of $17 \mathrm{mM}$ every 2 days. Then, plants were subjected to the final treatment concentration for 2 months before following measurements were taken.

\subsection{Measurements}

Photosynthetic gas exchange of the most recently expanded terminal trifoliate leaflet was measured between 8 a.m. and 5 p.m. using a steady-state open gas exchange system (Kao and Tsai, 1998). The system consisted of an infrared carbon dioxide analyzer (LI-6262, Licor, Lincoln, NE) and a leaf chamber (Pacsys 9900, DDG, La Jolla, CA) with integral temperature and humidity sensor. The rates of photosaturated photosynthetic carbon assimilation $\left(A_{\max }\right)$ and stomatal conductance $\left(g_{\mathrm{s}}\right)$ were determined by enclosing the leaf in a cuvette under a photon flux of $1200 \mu \mathrm{mol} \mathrm{m}^{-2} \mathrm{~s}^{-1}$, with light provided from a fibre illuminator (FL-440, Walz, Germany). Measurement conditions within the cuvette were: leaf temperature $30^{\circ} \mathrm{C}$, leaf-to-air water vapor pressure difference $1-1.2 \mathrm{kPa}$, and ambient $\mathrm{CO}_{2}$ concentration $360 \pm 5 \mathrm{~cm}^{3} \mathrm{~m}^{-3}$. After steady-state rates of $A_{\max }$ had been recorded (about $1 \mathrm{~h}$ ), leaves were removed from the cuvette and excised leaf area was measured using a leaf area meter (LI-3100, Licor, Lincoln, NE). The leaf was then dried at $60^{\circ} \mathrm{C}$ for at least $48 \mathrm{~h}$ and ground to powder for ion content analysis.

Ions were extracted from leaves at a temperature of $80^{\circ} \mathrm{C}$ from a $\mathrm{HCl}(6 \mathrm{M})$ solution (Lambert, 1976). Potassium and $\mathrm{Na}$ contents were subsequently analyzed with a flame photometer (Model 410, Corning, England), and Ca analyzed by atomic absorption (Model 2380, Perkin-Elmer).

Plant shoots and roots were harvested after 2 months of salinity treatment, dried at $60{ }^{\circ} \mathrm{C}$ for 7 days and then weighed for determination of dry biomass.

All statistical tests were performed using the computer software SYSTAT (Statistical Solution Limited, Ireland). Means were compared using the least significant difference test. Significant levels are reported as $P<0.05$.

\section{Results}

\subsection{Leaf size}

Leaf size differed among species and with $\mathrm{NaCl}$ treatment (Table 1). Increasing $\mathrm{NaCl}$ concentration resulted in reduced leaf size for $G$. soja, as a consequence, plants received no $\mathrm{NaCl}$ had the largest and those with $85 \mathrm{mM}$ the smallest leaf area (Table 1). In $G$. tomentella, no significant difference was found in leaf size among 0,17 and $51 \mathrm{mM}$ treated plants,

Table 1

Leaf area (mean \pm S.E., $n=4, \mathrm{~cm}^{2}$ ) of the most recent, fully expanded trifoliate leaf of wild soybeans after 2 months of different $\mathrm{NaCl}$ treatments

\begin{tabular}{|c|c|c|c|c|}
\hline \multirow[t]{2}{*}{ Species } & \multicolumn{4}{|l|}{$\mathrm{NaCl}(\mathrm{mM})$} \\
\hline & 0 & 17 & 51 & 85 \\
\hline G. soja & $11.8 \pm 0.6$ & $6.6 \pm 1.0$ & $3.0 \pm 0.3$ & $2.1 \pm 0.4$ \\
\hline G. tomentella & $10.2 \pm 0.9$ & $11.6 \pm 0.7$ & $10.0 \pm 0.9$ & $6.7 \pm 1.9$ \\
\hline G. tabacina & $4.5 \pm 0.2$ & $4.4 \pm 0.2$ & $4.0 \pm 0.3$ & $4.2 \pm 0.4$ \\
\hline
\end{tabular}



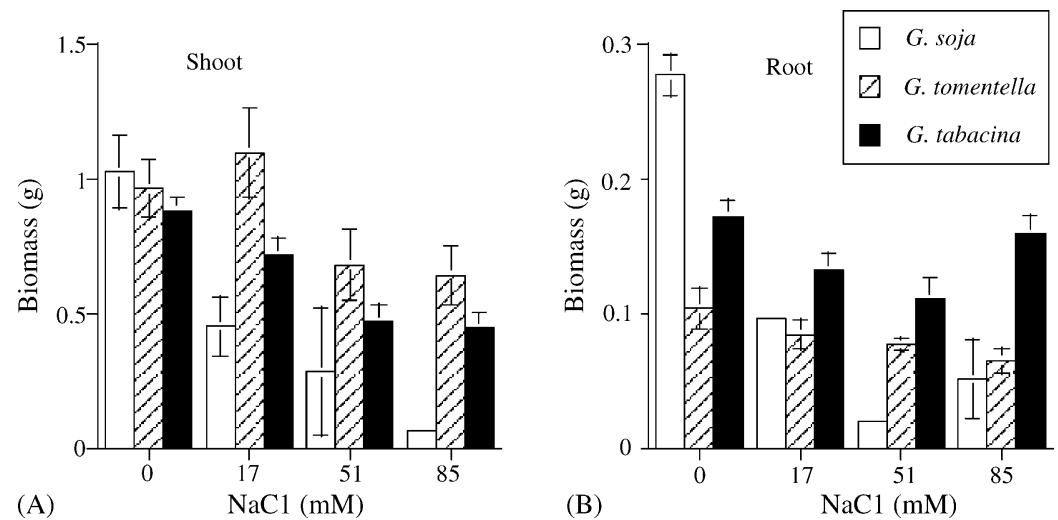

Fig. 1. Accumulated shoot (A) and root (B) biomass of three soybean species, G. soja (open bar), G. tabacina (closed bar), and G. tomentella (hatched bar), exposed to four $\mathrm{NaCl}$ treatments over 2 months. Vertical bars represent 1 S.E. of treatment $(n=4)$.

however, $85 \mathrm{mM} \mathrm{NaCl}$ had significantly smaller leaf sizes compared to other treatments. No significant difference was found in leaf size among plants of G. tabacina in the four different regimes of $\mathrm{NaCl}$ (Table 1).

\subsection{Biomass}

Adding $\mathrm{NaCl}$ to culture medium significantly reduced both root and shoot biomass of G. soja, and the reduction increased with increasing salinity (Fig. $1 \mathrm{~A}$ ). $\mathrm{NaCl}$ treatments had no significant effect on root biomass of G. tabacina and G. tomentella (Fig. 1B). However, shoot biomass in 17, 51 and $85 \mathrm{mM} \mathrm{NaCl}$ treated $G$. tabacina were significantly lower than that of $0 \mathrm{mM}$ plants (Fig. 1A). In G. tomentella, $17 \mathrm{mM}$ treatment did not differ from controls for shoot biomass, however, 51 and $85 \mathrm{mM}$ treatments resulted in significantly lower shoot biomass than controls and $17 \mathrm{mM}$ treatments (Fig. 1A).

\subsection{Photosynthetic gas exchange}

Photosaturated photosynthetic rates were similar among the three species in the $0 \mathrm{mM}$ treatment (Fig. 2A). However, stomatal conductance in this treatment was significantly higher in G. soja and G. tomentella than that in G. tabacina
Table 2

The ratio of $C_{\mathrm{i}} / C_{\mathrm{a}}$ (mean \pm S.E., $\left.n=4\right)$ of the most recent, fully expanded trifoliate leaf of wild soybeans after receiving different regimes of $\mathrm{NaCl}$ treatment

\begin{tabular}{lllll}
\hline Species & \multicolumn{2}{l}{$\mathrm{NaCl}(\mathrm{mM})$} & & \\
\cline { 2 - 5 } & 0 & 17 & 51 & 85 \\
\hline G. soja & $0.67 \pm 0.02$ & $0.72 \pm 0.01$ & $\mathrm{NA}$ & $\mathrm{NA}$ \\
G. tomentella & $0.63 \pm 0.01$ & $0.57 \pm 0.01$ & $0.58 \pm 0.01$ & $0.58 \pm 0.01$ \\
G. tabacina & $0.60 \pm 0.02$ & $0.58 \pm 0.02$ & $0.57 \pm 0.04$ & $0.57 \pm 0.02$ \\
\hline
\end{tabular}

NA: not available.

(Fig. 2B). $A_{\max }$ and $g_{\mathrm{S}}$ of the three species responded differently to the $\mathrm{NaCl}$ treatments. Leaves of $G$. soja in the 51 and $85 \mathrm{mM}$ treatments were too small to conduct photosynthetic measurements, while those in the $17 \mathrm{mM}$ treatment had significantly lower $A_{\max }$ and $g_{\mathrm{s}}$ than those of $0 \mathrm{mM}$ treated plants. The reduction in $A_{\max }$ was relatively greater than that in $g_{\mathrm{s}}$; as a consequence, the ratio of intercellular to ambient $\mathrm{CO}_{2}$ concentration $\left(C_{\mathrm{i}} / C_{\mathrm{a}}\right)$ of $17 \mathrm{mM}$ treated $G$. soja increased (Table 2). In contrast, 0,17 and $51 \mathrm{mM} \mathrm{NaCl}$ treated G. tomentella and G. tabacina had similar $A_{\max }$ and $g_{\mathrm{s}}$, with only $85 \mathrm{mM}$ treated plants showing significantly lower $A_{\max }$ and $g_{\mathrm{s}}$ (Fig. 2). No significant differences were found in the ratio of $C_{\mathrm{i}} / C_{\mathrm{a}}$ among $G$. tabacina plants from the four treat-
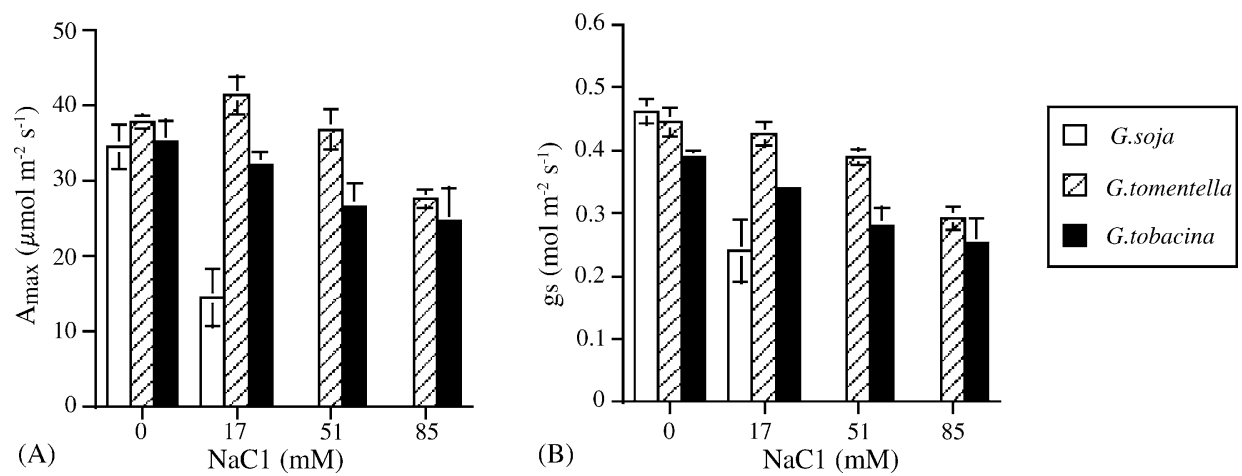

Fig. 2. Effect of four $\mathrm{NaCl}$ treatments on photosaturated photosynthetic rate $\left(A_{\max }\right)(\mathrm{A})$ and stomatal conductance (B) of three wild soybean species, $G$. soja (open bar), G. tabacina (closed bar), and G. tomentella (hatched bar). Vertical bars represent mean $(n=4) \pm$ S.E. 

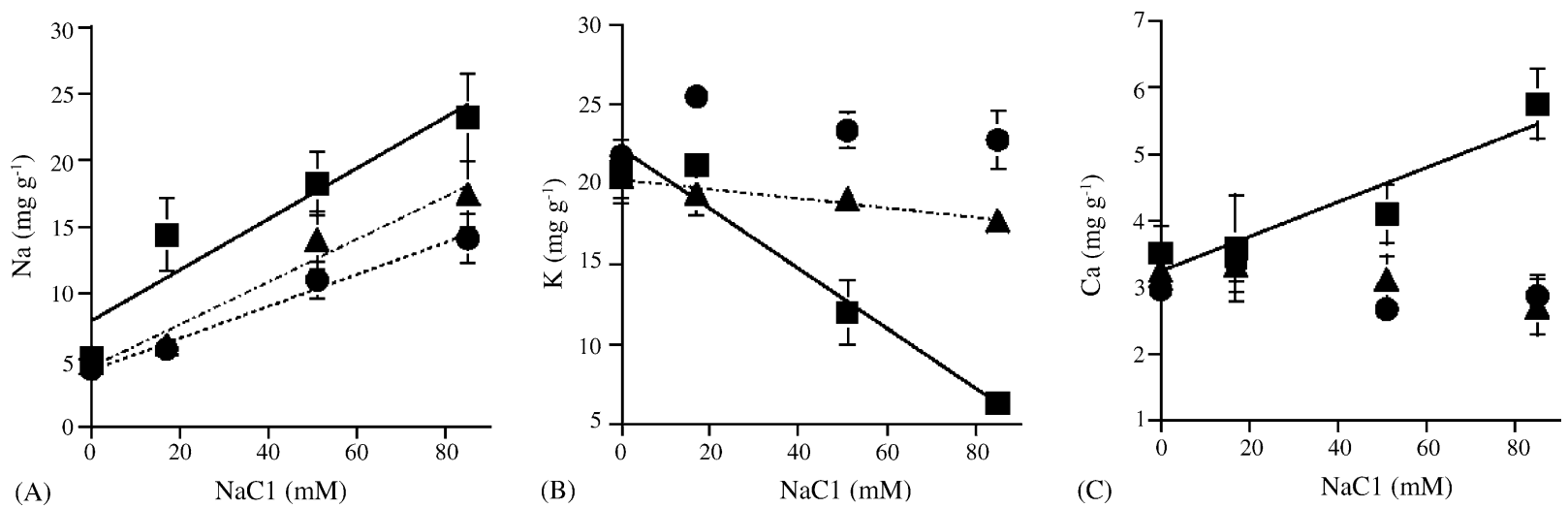

Fig. 3. The correlation between leaf $\mathrm{Na}$ (A), $\mathrm{K}$ (B) and $\mathrm{Ca}$ (C) contents and $\mathrm{NaCl}$ treatment for G. soja (square), G. tabacina (triangle), and G. tomentella (circle). Solid lines are significant regressions fit to the pooled data from all $\mathrm{NaCl}$ treatments.

ments (Table 2). In G. tomentella, all $\mathrm{NaCl}$ treatments above $0 \mathrm{mM}$ resulted in significant reductions in $C_{\mathrm{i}} / C_{\mathrm{a}}$, although there was no further decrease with increased $\mathrm{NaCl}$ concentration (Table 2).

\subsection{Leaf $\mathrm{Na}, \mathrm{K}$ and $\mathrm{Ca}$ contents}

No significant difference was found in leaf $\mathrm{Na}$ contents among the three species in the $0 \mathrm{mM} \mathrm{NaCl}$ treatment (Fig. 3A). The Na concentration in leaves of the three species increased with increasing $\mathrm{NaCl}$, resulting in positive correlations between leaf $\mathrm{Na}$ content and $\mathrm{NaCl}$ concentration in all three species. G. soja accumulated more Na than $G$. tomentella and G. tabacina.

No significant difference in leaf $\mathrm{K}$ contents was measured among the three species in $0 \mathrm{mM} \mathrm{NaCl}$ treatment (Fig. 3B). Increasing $\mathrm{NaCl}$ concentration in the treatments decreased leaf $\mathrm{K}$ contents in G. soja and G. tabacina, with the degree of reduction higher in G. soja than in G. tabacina. As a result, leaf $\mathrm{K}$ contents were highest in $G$. tomentella, intermediate in G. tabacina, and lowest in G. soja.

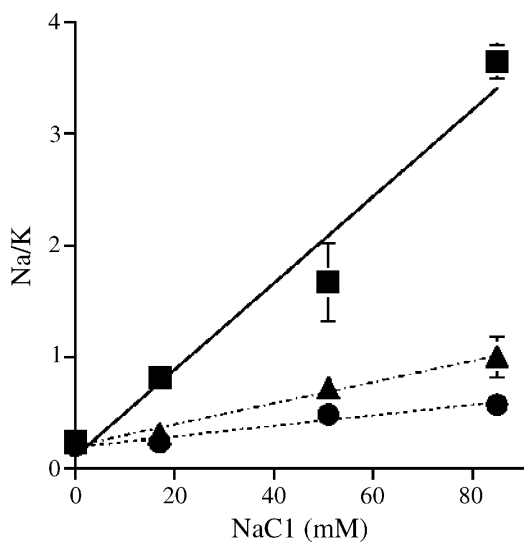

Fig. 4. The correlation between the ratio of $\mathrm{Na} / \mathrm{K}$ in leaves and $\mathrm{NaCl}$ concentration in four different treatments for G. soja (square), G. tabacina (triangle), and $G$. tomentella (circle). Solid lines are significant regressions fit to the pooled data from all $\mathrm{NaCl}$ treatments.
No significant difference was found in leaf $\mathrm{Ca}$ contents among the three species on the $0 \mathrm{mM} \mathrm{NaCl}$ treatment (Fig. 3C). Increasing $\mathrm{NaCl}$ concentration in the treatments increased leaf Ca contents in G. soja, however, no correlations were found in G. tabacina and G. tomentella.

No significant difference was found in the ratio of $\mathrm{Na} / \mathrm{K}$ in leaves for the three species in the $0 \mathrm{mM} \mathrm{NaCl}$ treatment (Fig. 4). The ratio of $\mathrm{Na} / \mathrm{K}$ in leaves of all three species increased significantly with increasing treatment $\mathrm{NaCl}$ concentration, with the greatest increment in G. soja, the least in G. tomentella.

\section{Discussion}

Results from this study showed that $85 \mathrm{mM} \mathrm{NaCl}$ treatment caused reductions in growth of all three wild soybean species (Table 1; Fig. 1). This is consistent with previous reports that soybeans are glycophytes (Läuchli and Wieneke, 1979). However, our results also showed that the susceptibility to salt stress differed among the three species. $G$. soja appeared to be the most salt sensitive, with reduced leaf expansion (Table 1), photosynthetic rates (Fig. 2), and biomass (Fig. 1) in response to exposure to $\mathrm{NaCl}$. These reductions increased with increasing $\mathrm{NaCl}$ concentration. The response of G. tomentella and G. tabacina to $\mathrm{NaCl}$ treatment differed from that of G. soja. Though their growth was also reduced at the highest $\mathrm{NaCl}$ concentrations used (51 and $85 \mathrm{mM}$ ), a slight or no decrease in biomass was found between 17 and $0 \mathrm{mM}$ treated plants. This result supports the hypothesis that the three wild soybeans in Taiwan have differentiated in their sensitivity to salinity, with $G$. soja the most, G. tabacina intermediate, and G. tomentella the least sensitive. This corresponds to field observations that $G$. tomentella is the only species found growing in seaside habitats.

The reductions in growth due to $\mathrm{NaCl}$ treatment (Table 1; Fig. 1) were consistent with differences in the sensitivity of $A_{\max }$ among the species (Fig. 2). However, the inhibition of $A_{\max }$ may be due to different mechanisms in different 
species. Analysis of gas exchange measurements revealed that decreased photosynthesis in $G$. tomentella might not be caused by ion toxicity but by salinity-induced reductions in $g_{\mathrm{s}}$ (a greater relative reduction in $g_{\mathrm{s}}$ than in $A_{\max }$ and concomitantly a lower ratio of $C_{\mathrm{i}} / C_{\mathrm{a}}$ ) (Fig. 2; Table 2 ). Similar results were found in the salt-sensitive species, Phaseolus vulgaris $\mathrm{L}$. (Seemann and Critchley, 1985; Brugnoli and Lauteri, 1991) and spinach leaves (Downton et al., 1985) in response to salinity. In contrast, the greater relative reductions in $A_{\max }$ than in $g_{\mathrm{s}}$ and consequently higher ratio of $C_{\mathrm{i}} / C_{\mathrm{a}}$ (Table 2 ) measured in $G$. soja suggests that non-stomatal inhibition of photosynthesis, caused by direct effects of $\mathrm{NaCl}$ on the photosynthetic apparatus independent of stomatal closure, might be responsible for the reduction in photosynthetic rate of $\mathrm{NaCl}$ treated G. soja. Non-stomatal inhibition of photosynthesis by salinity has also been reported for several plant species (Seemann and Critchley, 1985; Ball and Anderson, 1986). This inhibition of photosynthetic capacity may result from a reduced efficiency of ribulose-1,5-bisphosphate (RuBP) carboxylase, or a reduction of RuBP regeneration capacity, or to the sensitivity of PSII to $\mathrm{NaCl}$ (Ball and Anderson, 1986). The $C_{\mathrm{i}} / C_{\mathrm{a}}$ ratio declined slightly in $\mathrm{NaCl}$ treated $G$. tabacina compared to $0 \mathrm{mM}$ treatments, however, no significant difference was detected in this ratio as $\mathrm{NaCl}$ increased from 17 to $85 \mathrm{mM}$ (Table 2). This implies that the reduction of $A_{\max }$ by salinity treatment in this species was caused by both stomatal and non-stomatal factors.

Results from this study showed a different ranking among the three soybean species in their sensitivity to salinity compared to their susceptibility to low water availability. While G. soja was the most susceptible to both salinity and low water availability, G. tabacina and G. tomentella reversed positions (Kao and Tsai, 1998). Thus, similar to the finding in wheat (Nagy and Galiba, 1995), drought and salt tolerance are not necessarily linked among these three species of wild soybean.

Differences in the accumulation of $\mathrm{Na}$ and $\mathrm{K}$ in leaves of the three species (Fig. 3A and B) may contribute to their differential responses. A negative correlation between $\mathrm{Na}$ accumulation in leaves and salt tolerance was found (Figs. 1 and 3A), with the most sensitive species, G. soja, accumulating the most, and the least sensitive species, $G$. tomentella accumulating the least (Fig. 3A). This is consistent with findings in many crop species (Hajibagheri et al., 1987; Schachtman and Munns, 1992).

Salinity can interfere with $\mathrm{K}$ and Ca nutrition (Rengel, 1992). Potassium is an activator of many enzymes that are essential for photosynthesis and respiration, and deficiencies in $\mathrm{K}$ would result in inhibition of photosynthesis and eventually reduction in growth (Salisbury and Ross, 1992). The maintenance of a high $\mathrm{K}$ content may be crucial to sustain the integrity of the photosynthetic system under high salinity (Chow et al., 1990) and thus an important pre-requisite for salinity tolerance. Results from present investigation showed higher $\mathrm{Na}$ and lower $\mathrm{K}$ contents in the leaf tissue of G. soja compared to G. tomentella and G. tabacina (Fig. 4). This result implies that the differential accumulation of leaf $\mathrm{Na}$ and $\mathrm{K}$ might be responsible for the different sensitivity of the three wild soybeans to $\mathrm{NaCl}$ treatment. Similarly, Gregorio and Senadhira (1993) found that in rice varieties the higher the level of salinity tolerance the lower the $\mathrm{Na}$ content and the higher the $\mathrm{K}$ content in the shoot.

Salinity impairs the uptake of Ca by plants (Cramer et al., 1987). Suhayda et al. (1992) and Huang and Redmann (1995) suggested that salinity-induced symptoms in cultivated barley may be the result of a Ca deficiency. In this study, we found no significant effect of salinity on Ca contents in G. tomentella and G. tabacina (Fig. 3C). In contrast, there were increases in Ca content in the most salt-sensitive species, $G$. soja, in response to salinity treatment (Fig. 3C). Sweet clover, which showed no effect of salt on Ca uptake, actually increased $\mathrm{Ca}$ uptake during the reproductive phase (Romero and Maranon, 1994). Accordingly, salinity-induced deficiency of Ca was not evident in the wild soybeans measured.

In conclusion, growth and photosynthesis of three wild soybean species differ in their response to $\mathrm{NaCl}$ treatments. $G$. soja was the most sensitive species, G. tabacina intermediate, and $G$. tomentella the least to $\mathrm{NaCl}$ treatment. Differences among species in leaf accumulation of $\mathrm{Na}$ and $\mathrm{K}$ might be responsible for the differential sensitivity to $\mathrm{NaCl}$ treatments.

\section{Acknowledgements}

We thank Dr. Yue-Ie Hsing for supplying soybean seeds used in this study, and Dr. Irwin Forseth for editing the manuscript. The manuscript greatly benefited from the suggestions of two anonymous reviewers.

\section{References}

Bongi, G., Loreto, F., 1989. Gas-exchange properties of salt-stressed olive (Olea europea L.) leaves. Plant Physiol. 90, 1408-1416.

Brugnoli, E., Lauteri, M., 1991. Effects of salinity on stomatal conductance, photosynthetic capacity, and carbon isotope discrimination of salt-tolerance (Gossypium hirsutum L.) and salt-sensitive (Phaseolus vulgaris L.) $\mathrm{C}_{3}$ non-halophytes. Plant Physiol. 95, 628-635.

Ball, M.C., Anderson, J.M., 1986. Sensitivity of photosystem II to $\mathrm{NaCl}$ in relation to salinity tolerance. Comparative studies with thylakoids of the salt-tolerant mangrove, Avicennia marina, and the salt-sensitive pea, Pisum sativum. Aust. J. Plant Physiol. 13, 689-698.

Chow, W.S., Ball, M.C., Anderson, J.M., 1990. Growth and photosynthetic responses of spinach to salinity: implication of $\mathrm{K}^{+}$nutrition for salt tolerance. Aust. J. Plant Physiol. 17, 563-578.

Cramer, G.R., Lynch, J., Lauchli, A., Epstein, E., 1987. Influx of $\mathrm{Na}^{+}$, $\mathrm{K}^{+}$and $\mathrm{Ca}^{2+}$ into roots of salt stressed cotton seedlings. Effects of supplemental $\mathrm{Ca}^{2+}$. Plant Physiol. 79, 171-176.

Downton, W.J.S., Grant, W.J.R., Robinson, S.P., 1985. Photosynthetic and stomatal responses of spinach leaves to salt stress. Plant Physiol. 77, 85-88.

Flowers, T.J., Hajibagheri, M.A., 2001. Salinity tolerance in Hordeum vulgare: ion concentrations in root cells of cultivars differing in salt tolerance. Plant Soil 231, 1-9.

Fortmeier, R., Schubert, S., 1995. Salt tolerance of maize (Zea mays L.): the role of sodium exclusion. Plant Cell Environ. 18, 1041-1047. 
Gorham, J., Papa, R., Aloy-Leonart, M., 1994. Varietal differences in sodium uptake in barley cultivars exposed to soil salinity or salt spray. J. Exp. Bot. 45, 895-901.

Gregorio, G.B., Senadhira, D., 1993. Genetic analysis of salinity tolerance in rice (O. sativa L.). Theor. Appl. Genet. 86, 333-338.

Haines, B., Dunn, E.L., 1976. Growth and resource allocation responses of Spartina alterniflora Loisel to three levels of $\mathrm{NH}_{4}-\mathrm{N}, \mathrm{Fe}$ and $\mathrm{NaCl}$ in solution culture. Got. Gaz. 137, 224-230.

Hajibagheri, M.A., Harvey, D.M.R., Flowers, T.J., 1987. Quantitative ion distribution within root cells of salt-sensitive and salt-tolerant maize varieties. New Phyt. 105, 367-379.

Huang, J., Redmann, R.E., 1995. Responses of growth, morphology, and anatomy to salinity and calcium supply in cultivated and wild barley. Can. J. Bot. 73, 1859-1866.

Huang, T.C., Ohashi, H., 1993. Leguminosae. In: Huang, T.C. (Ed.), Flora of Taiwan, vol. III. Editorial Committee of the Flora of Taiwan, Taipei, pp. 160-396.

Kao, W.Y., Tsai, T.T., 1998. Tropic leaf movements, photosynthetic gas exchange, leaf $\delta^{13} \mathrm{C}$ and chlorophyll a fluorescence of three soybean species in response to water availability. Plant Cell Environ. 21, 1055-1062.

Lambert, M.J., 1976. Preparation of Plant Material for Estimating a Wide Range of Elements. For. Comm. New South Wales, West Pennant Hills, Australian Research Note 29.

Läuchli, A., Wieneke, J., 1979. Studies on growth and distribution of $\mathrm{Na}^{+} \mathrm{K}^{+}$and $\mathrm{Cl}^{-}$in soybean varieties differing in salt tolerance. $\mathrm{Z}$. Pflanzenernaehr. Bodenkd. 142, 3-13.

Lee, K.S., Choi, W.Y., Ko, J.C., Kim, T.S., Gregorio, G.B., 2003. Salinity tolerance of japonica and indica rice (Oryza sativa L.) at the seedling stage. Planta 216, 1043-1046.
Munns, R., 2002. Comparative physiology of salt and water stress. Plant Cell Environ. 25, 239-250.

Nagy, Z., Galiba, G., 1995. Drought and salt tolerance are not necessarily linked: a study on wheat varieties differing in drought tolerance under consecutive water and salinity stresses. J. Plant Physiol. 145, 168174

Rengel, Z., 1992. The role of calcium in salt toxicity. Plant Cell Environ. 15, 625-632.

Romero, J.M., Maranon, T., 1994. Long-term responses of Melilotus segitalis to salinity. II. Nutrient absorption and utilization. Plant Cell Environ. 17, 1249-1255.

Salisbury, F.B., Ross, C.W., 1992. Mineral nutrient. In: Plant Physiology. Wadsworth Inc., California, pp. 116-135.

Schachtman, D.P., Munns, R., 1992. Sodium accumulation in leaves of Triticum species that differ in salt tolerance. Aust J. Plant Physiol. 19, 331-340.

Seemann, J.R., Critchley, C., 1985. Effects of salt stress on the growth, ion content, stomatal behavior and photosynthetic capacity of a salt-sensitive species Phaseolus vulgaris L. Planta 164, 151162

Suhayda, C.G., Redmann, R.E., Harvey, B.L., Cipywnyk, A.L., 1992. Comparative response of cultivated and wild barley species to salinity stress and calcium supply. Crop Sci. 32, 154-163.

Szabolcs, I., 1994. Soils and salinization. In: Pessarakli, M. (Ed.), Handbook of Plant and Crop Stress. Marcel Dekker, New York, pp. 3-11.

Tester, M., Davenport, R., 2003. $\mathrm{Na}^{+}$tolerance and $\mathrm{Na}^{+}$transport in higher plants. Ann. Bot. 91, 503-527.

Walker, R.R., Törökfalvy, E., Scott, N.S., Kriedemann, P.E., 1981. An analysis of photosynthetic response to salt treatment in Vitis vinifera. Aust. J. Plant Physiol. 8, 359-374. 